\title{
Enabling information sharing by establishing trust in supply chains: A case study in the South African automotive industry
}

\author{
Authors: \\ Roxanne Piderit ${ }^{1}$ \\ Stephen Flowerday ${ }^{1}$ \\ Rossouw von Solms ${ }^{2}$ \\ Affiliations: \\ ${ }^{1}$ Department of Information \\ Systems, University of Fort \\ Hare, South Africa \\ ${ }^{2}$ School of Information \\ and Communication \\ Technology, Nelson Mandela \\ Metropolitan University, \\ South Africa \\ Correspondence to: \\ Roxanne Piderit \\ Email: \\ rpiderit@ufh.ac.za \\ Postal address: \\ 50 Church Street, East \\ London 5201, South Africa \\ Dates: \\ Received: 11 Feb. 2011 \\ Accepted: 21 June 2011 \\ Published: 12 Oct. 2011 \\ How to cite this article: \\ Piderit, R., Flowerday, S. \\ \& Von Solms, R., 2011, \\ 'Enabling information sharing \\ by establishing trust in \\ supply chains: A case study in \\ the South African automotive \\ industry', SA Journal of \\ Information Management \\ 13(1), Art. \#473, 8 pages. \\ doi:10.4102/sajim.v13i1.473
}

(C) 2011. The Authors. Licensee: AOSIS OpenJournals. This work is licensed under the Creative Commons Attribution License.
Background: The significant economic importance of the country's automotive industry provided the context for this study. The success of the industry relies on the effectiveness and efficiency of the supply chain, which can be significantly affected by the strength of the supply chain relationships. The role of trust and information sharing in relation to two key theories was considered, namely: organisational information processing theory and game theory. Previous studies have recognised the importance of trust and information sharing in supply chain relationships and considered the effect of trust on information sharing, or the effect of information sharing on trust in a single direction. Thus, the potential cyclical relationship between the two factors has been largely ignored.

Objectives: This paper explored the relationship between trust and information sharing in South African automotive supply chains, and establishes the importance of nurturing a cyclical relationship between these two factors. In addition, the role of information technology (IT) in supporting this relationship was considered. By improving both trust and information sharing, the performance and competitiveness of the supply chain can be improved.

Method: An examination of the effects of a lack of trust in a supply chain relationship, and the consequential lack of information flow, was conducted by means of a case study of an Eastern Cape-based automotive supplier. A case study research method was followed for this study, which made use of multiple data collection methods, including document survey and participant observations. The case selected is an East London based subsidiary of a larger multinational automotive component supplier to both local and international automotive original equipment manufacturers.

Results: The findings led to the conclusion that the way forward for competitive supply chains is to build trust in the supply chain in order to improve information flow, and vice versa. Information technology can be used to nurture this cyclical relationship between trust and information sharing.

Conclusion: It is proposed that simultaneously improving information flow and trust in an interorganisational relationship leads to improved supply chain performance and competitiveness.

\section{Introduction}

Globally, governments are recognising the potential impact of automotive manufacturers on an economy and have become dedicated to attracting automakers to their countries and regions. For South Africa, attracting automotive manufacturers and their suppliers to invest in the country has become increasingly important (Barnes \& Morris 2008; Fingar 2002). Fingar (2002) discusses the social problems that are rife in South Africa, such as: high unemployment, rampant poverty and the HIV and AIDS epidemic. Significant foreign investment is required to overcome these social problems. In addition, the automotive sector accounts for 7\% of South Africa's gross domestic product and provides employment to more than 120000 workers (Barnes \& Morris 2008). Thus, the South African government has made the automotive industry a priority through various policy adjustments (Barnes \& Morris 2008; Lorentzen 2006), which are aimed at convincing multinational automotive manufacturers and suppliers to strengthen and deepen their South African operations (Lorentzen 2006). The operations of automotive manufacturers depend on a substantial network of suppliers. As these automotive supply chains can consist of over 300 suppliers, including first-, second- and third-tier suppliers, the cyclical relationship between trust and information sharing in this context, is the focus of this article. 
This cyclical trust-information sharing relationship is especially relevant in the automotive industry where manufacturers are under enormous pressure to reduce time to market (TTM), increase flexibility and lower costs in order to be competitive (Pagano \& Zagnoli 2001). Fachinelli, Ueltschy and Ueltschy (2007) view trust as a prerequisite for supply chain success. This is substantiated by Covey (2008) who notes that the existence of trust in the supply chain relationship leads to reduced costs and more efficient and effective operations.

Additionally, one needs to consider the role of IT in these interorganisational relationships. Cheng, Lai and Singh (2007) view the use of IT to conduct business transactions, share information and facilitate collaboration as the main determinants of a supply chain's effectiveness. Jharkharia and Shankar (2004) share this view and note that information sharing, supported by IT, is the chief enabler of the effective management of a supply chain. For this reason, there is a global trend toward the IT-enablement of supply chains. The role of IT in the support of a cyclical trust-information sharing relationship is a central concern of this study.

Premkumar, Ramamurthy and Saunders (2005) propose that in order to improve trust in a supply chain relationship, information flow should be enhanced. This can be accomplished by, for example, implementing integrated information systems to improve information flow and reduce uncertainty in the supply chain relationship. At present, information flow is restricted as a result of the competitive nature of the automotive industry. For example, basing decisions on information provided by forecasting systems may lead to the interpretation by supply chain partners that a company intends to compete (Gao \& Lee 2005). The result of this perceived threat could be a decreased level of trust in the supply chain relationship.

The economic importance of the South African automotive industry is widely recognised and highlights the significance of this research. This study sets out to explore the cyclical relationship between trust and information sharing in South African automotive supply chains and to consider ways in which efficiency can be improved through the use of the appropriate IT platforms. Following this introduction, the underlying problem is discussed, a brief background to the South African automotive industry is provided and the changing nature of supply chain governance structures is highlighted to provide context. An examination of the role of trust and information sharing in the supply chain context follows, including a discussion of the relevance of the organisational information processing theory and game theory in this context. The cyclical relationship between trust and information sharing is then investigated within the context of an Eastern Cape based automotive supplier. A preliminary solution is provided.

\section{The problem}

Ensuring that South Africa continues to be a viable production site for Original Equipment Manufacturers (OEMs) who have invested significantly in the economy is reliant on the local suppliers and supply chain dynamics. This view is supported by Ward (2009:1) from Toyota who states that 'the strength of the supply chain is critical to the success of the automotive industry in general and of Toyota South Africa in particular'. Furthermore, Mangold (2009:1) from Mercedes-Benz notes that 'local suppliers need to improve competitiveness to ensure that local OEMs can compete with their respective international counterparts'. These statements highlight the importance of ensuring that South African automotive supply chains function efficiently through the enhancement of trust between supply chain partners.

Insufficient trust amongst supply chain partners leads to inefficient and ineffective operations in the supply chain, and consequently impacts negatively on the supply chain's competitive advantage (Covey 2008). For this reason, South African automotive supply chains need to have a sufficient level of trust entrenched in the relationships amongst supply chain partners, in order to compete effectively against their global counterparts.

Information sharing can be disrupted through insufficient trust amongst supply chain partners (Fedorowicz \& Ghosh 2008). This leads to ineffective and inefficient operations in the supply chain, as insufficient information is available to all supply chain partners in order to make effective decisions. Insufficient information sharing can thus be viewed as detrimental to the supply chain's competitiveness.

Thus, both insufficient trust and insufficient information sharing are viewed as contributing factors to the ineffectiveness and inefficiency of a supply chain's operations, and the resultant negative effect on competitive advantage. Additionally, the cyclical nature of the relationship between trust and information sharing emerges.

\section{The method}

A case study research method was followed for this study of the relationship between trust and information sharing in South African automotive supply chains. Kazi \& Wolf (2004) point out that a case study can effectively extract examples of both good and bad practice. This is considered appropriate in the context of this research, where an in-depth study of the context is required. Thus, a deeper understanding of the phenomenon under investigation was sought (Cooper \& Schindler 2003).

The case itself is a small East London-based subsidiary of a larger multinational automotive component supplier to both local and international automotive OEMs. This case was selected because of the researcher's involvement in the Programme for Industrial Manufacturing Excellence (PRIME), which gave initial access to the organisation. Subsequent involvement with the supplier was, however independent of this programme. This case is considered to be representative of issues faced in similar component suppliers (based on a pilot study conducted at another local supplier and involvement in PRIME). Thus, as pointed out by Cooper 
and Schindler (2003), the selection of this case can lead to conclusions being drawn about the entire population.

The case study method allows the researcher to make use of various data collection methods to conduct the study. The methods employed were: document survey to provide insight into the organisations current information sharing practices, and participant observations to assess the effectiveness of these information sharing practices and the level of trust evident in supply chain.

As a result of the nature of the case and the data collection techniques chosen, it was not suitable to make use of statistical means of data analysis (Yin 2003). Thus, the data collected was analysed by making use of pattern-matching and logic models as proposed by Yin (2003).

\section{The South African automotive industry}

Many multinational automotive OEMs and component suppliers have realised that operations in South Africa can provide an opportunity for competitive advantage (DTI 2005). Relative to the size of the South African market, the automotive sector continues to perform well, and has set the standard for the development of other industries within the country (Africa Research Bulletin 2010), and thus, the Department of Trade and Industry (DTI 2005) believes that national, provincial and local governments should continue to ensure the success of this sector. Despite the economic slump in 2009, the automotive industry has recovered well and vehicle sales have continued to grow and indicate sustainable growth (Africa Research Bulletin 2010).

Besides economic benefits, the automotive sector (which includes both the component suppliers and the assembly operations) is widely viewed as the second biggest employer in South Africa after mining (DTI 2005). Mercedes-Benz South Africa's East London assembly operation is the largest private sector employer in the Eastern Cape and has invested considerably in relieving the socio-economic issues faced by the local community (Mak'Ochieng 2003). The primary challenge the automotive industry faces is the increased exposure to international competition since the introduction of the Motor Industry Development Programme (MIDP) in 1995 (Black 1998).

The MIDP was modelled on a similar attempt in Australia, known as the Automotive Investment and Competitiveness Scheme (Fingar 2002; Franse 2006). This scheme ensured the Australian automotive industry was competitive by awarding import credits to those organisations that performed satisfactorily (Fingar 2002). The structural changes and resultant sheltered atmosphere of the South African automotive industry encouraged automotive OEMs to invest in the country (Franse 2006). The MIDP has since been replaced by the Automotive Investment Scheme (AIS). The AIS is intended to grow and develop the automotive sector through investment in new and replacement automotive models as well as the manufacturing of automotive components (DTI 2010).

Other challenges for the automotive industry include the growth of Asian competitors, limited production capacity, price pressures enforced by multinational partners in order to retain business, soaring oil and raw material prices, skill shortages and a somewhat volatile work force (Ford Motor Company 2005). The influence of Asian manufacturers has resulted in the need to adopt lean principles and 'justin-time' approaches in order to be competitive which has provided a challenge for the more traditional manufacturers (Burnes \& West 2000). These traditional manufacturers also need to ensure that their employees can adapt to these changes (Burnes \& West 2000). The Asian manufacturers have managed to reduce costs dramatically and have thus caused concern for the continued viability of South Africa's automotive sector (Franse 2006).

The changing nature of the industry has also required an evolution of the governance structure of supply chains. Peterson (2002) recognises that supply chains have moved beyond the traditional channel master model, where the OEM dominates and specifies the terms of trade across the whole supply chain, to a chain organism model, where there is no dominant organisation and the OEM needs to form strong relationships with the suppliers. Dubey and Jain (2005) conceptualise interorganisational governance as a multidimensional phenomenon that is manifested in structure, processes and contracts. In terms of governance, Dubey and Jain (2005) view a supply chain as either:

- a business network, in which each organisation is autonomous, that collectively addresses problems in the absence of an overarching authority and in which, therefore, there is a need for interorganisational governance; or

- an extended enterprise, in which a local organisation has many stakeholders (including buyers, suppliers, and subcontractors), and thus requires corporate governance to maximise the benefits to the stakeholders.

Decentralising control (as in the business network model described above) allows the supply chain to adapt to unforeseen circumstances, but decentralised decisions often result in suboptimum outcomes at the supply chain level including an increased level of competition between supply chain partners (Gao \& Lee 2005). Ryu (2006) considered how a change in the external circumstances of the supply chain affects differing levels of interdependence amongst supply chain participants and found that where the organisations have a low level of interdependence, a change in external circumstances prompts the manufacturers to increase the level of monitoring of their suppliers. However, where the organisations have a high level of interdependence, environmental uncertainty had little or no effect on the level of monitoring (Ryu 2006). Similarly, with the decentralised business network model, a high level of trust, will allow the supply chain to operate efficiently and thus compete effectively in the marketplace. 


\section{The role of trust and information sharing in the supply chain}

Recent years have seen a shift in the research focus in supply chain management from inter-functional to interorganisational integration and co-ordination (Dubey \& Jain 2005). Furthermore, there has been an increased interest in the role of trust in facilitating supply chain partnerships (Sahay 2003). Chu and Fang (2006) acknowledge that insufficient trust amongst supply chain partners leads to inefficient and ineffective performance. Covey (2008) emphasises that a sufficient level of trust in an interorganisational relationship can reduce costs and save time. Thus, trust emerges as an essential element in governing interorganisational relationships in supply chains (Fedorowicz \& Ghosh 2008). Additionally, Agarwal and Shankar (2003) view the lack of personal interaction and geographic dispersion of supply chain members to be key elements that hinder the development of trust in these interorganisational relationships. As trust plays an obvious role in efficient supply chains, it is important to investigate it in more detail.

\section{Defining trust}

Han, Liu, Sun and Yu (2006) and Smeltzer (1997) acknowledge that although the social sciences have offered definitions and classifications of trust, there is little or no consensus on a definition of trust in a business or supply chain context. It is however acknowledged that a few researchers have made tentative attempts at defining trust (Smeltzer 1997).

Hosmer (1995 in Smeltzer 1997) provides a definition of trust based on organisational theory and philosophy:

Trust is the expectation by one person, group, or firm of ethically justifiable behaviour - that is, morally correct decisions and actions based upon ethical principles of analysis - on the part of the other person, group or firm in a joint endeavour or economic exchange.

(cited in Smeltzer 1997:41)

McEvily and Tortoriello (2011) conducted a review of organisational literature on trust. Amongst the definitions commonly adopted in organisational literature was that of Rosseau, Burt, Sitkin and Camerer (1998 cited in McEvily \& Tortoriello 2011): 'Trust is a psychological state comprising the intention to accept vulnerability based upon positive expectations of the intentions or behaviours of another'.
Ring and VanDe Ven (1994 cited in Smeltzer 1997) provide two additional views of trust. The first is based on confidence or risk in the predictability of the other party's actions, and in this instance parties hedge themselves against uncertain events through guarantees, insurance or law (Smeltzer 1997). The second view is based on confidence in the other party's goodwill, which relies on faith in the integrity of the other party (Smeltzer 1997).

Davis, Mayer and Schoorman (2007:346) concur with Ring and VanDe Ven's first view of trust and define it as the 'willingness to take risk'. As this has been determined to be the most commonly adopted definition of trust in organisational literature (McEvily \& Tortoriello 2011), this study has adopted this definition of trust. Based on this definition of trust; the value of trust in supply chain relationships needs to be considered.

The importance of trust in supply chainsThe importance of trust in governing interorganisational relationships can not be ignored. Fedorowicz and Ghosh (2008) explore the key constructs that support the governance of information sharing and material flow coordination in supply chains, which include: trust, bargaining power and contract. Furthermore, it is argued that trust as a governance mechanism plays a crucial role in sharing information amongst business partners (Fedorowicz \& Ghosh 2008). In support of this view, Wang and Wei (2007) established that interorganisational governance can create value through information visibility and supply chain flexibility.

To determine the important concepts in supply chain relationships, we conducted a basic content analysis of key articles in the area of supply chain management to identify which concepts are the most prominent in this relationship.

Trust emerges as the dominant concept in this content analysis of research into supply chain relationships, with information sharing as the second most important concept. This suggests the existence of a potentially important relationship between these two concepts.

\section{Determining the level of trust}

Several factors have been identified as determinants of the level of trust between supply chain partners, including perceived satisfaction, the reputation of supply chain

TABLE 1: Supply chain concepts (content analysis).

\begin{tabular}{|c|c|c|c|c|c|c|c|c|c|c|}
\hline Author & Trust & $\begin{array}{c}\text { Information } \\
\text { sharing }\end{array}$ & $\begin{array}{c}\text { Bargaining } \\
\text { power }\end{array}$ & Contract & $\begin{array}{c}\text { Relational } \\
\text { governance }\end{array}$ & Culture & $\begin{array}{l}\text { Decentralised } \\
\text { control }\end{array}$ & $\begin{array}{l}\text { Supply chain } \\
\text { Performance }\end{array}$ & Commitment & Uncertainty \\
\hline Chu \& Fang (2006) & $x$ & $x$ & - & - & - & - & - & $x$ & $x$ & - \\
\hline Dubey \& Jain (2005) & - & - & - & - & $x$ & - & - & - & - & - \\
\hline Fedorowicz \& Ghosh (2008) & $x$ & $x$ & $x$ & $x$ & - & - & - & - & - & - \\
\hline Gao \& Lee (2005) & $x$ & - & - & - & - & - & $x$ & - & - & - \\
\hline Kwon \& Suh (2005) & $x$ & $x$ & - & - & - & - & - & - & - & $\mathrm{x}$ \\
\hline Ryu (2006) & - & - & - & - & - & - & - & - & - & $\mathrm{x}$ \\
\hline Sahay (2003) & $x$ & $x$ & - & - & - & - & - & - & - & - \\
\hline Wang \& Wei (2007) & - & $x$ & - & - & $x$ & - & - & - & - & - \\
\hline
\end{tabular}


partners, and the level and quality of communication amongst these supply chain partners (Chu \& Fang 2006). Additionally, Kwon and Suh (2005) found that the level of trust amongst supply chain partners is highly reliant on the level of asset investment and information sharing structures. Information sharing, in particular, was found to play a role in reducing uncertainty in the supply chain relationship and thereby improving the level of trust (Kwon \& Suh 2005). Furthermore, Naesens, Pintelon and Taillieu (2007) also describe several determinants that affect the level of trust in supply chain relationships, including:

1. the supplier's performance history, which is an indicator of their reliability and competence

2. cumulative interactions, which are a valuable predictor of the supplier's behaviour

3. demonstrations of the supplier's good intentions, which create goodwill trust in the relationship

4. a transference process by which trust is based on other organisations' opinions of the supplier's trustworthiness.

These determinants emphasise the emergence of information sharing as a key factor in building trust in supply chain relationships. The role of IT in support of this trustinformation sharing relationship also needs to be considered.

\section{The role of information technology in support of trust and information sharing}

With the complicated network of suppliers that make up an automotive supply chain, the management of the multiple relationships is critical to the success of the supply chain (Dubey \& Jain 2005). It stands to reason that interorganisational systems will play an important role in maintaining these relationships between the supply chain partners. Various forms of information technology can play a role in reducing the impact of a lack of trust in the supply chain (Gao \& Lee 2005), such as forecasting systems. For this reason, the use of information technologies is proposed to overcome these inefficiencies (Gao \& Lee 2005).

Cheng et al. (2007) note that merely ensuring technology is used in supply chain management will not ensure that the supply chain is effective and efficient. It is therefore necessary to ensure that the correct IT has been implemented appropriately. Liu (2007) notes that Electronic Data Interchange (EDI), expert systems, communication technologies, database technology and network technology are required in order to ensure coordination of the entire supply chain and enhance the competitiveness of the supply chain as a whole.

\section{Organisational information processing theory}

The organisational information processing theory identifies information processing needs and capabilities and the need to obtain optimal performance through a balance of these factors. It views quality information as a requirement in handling uncertainty and improving decision-making. According to Premkumar et al. (2005), organisations have two strategies for dealing with this uncertainty, by either:
- developing buffers, for example inventory buffers to reduce the uncertainty related to demand and supply; or

- enhancing information flow, for example implementing integrated information systems to improve information flow and reduce uncertainty.

Similarly, in supply chains, improving information flow amongst supply chain partners reduces uncertainty in the relationships. This leads to the next subsection where game theory is used to illustrate the importance of information sharing and the concept of trust.

\section{Game theory and trust}

Game theory is used to study the choices that are made when costs and benefits are not fixed, but, rather, depend on other players (partners) and the shared information available to the players. According to Flowerday and Von Solms (2006), the amount of information that the various players have about each other is a key determinant of behaviour.

Flowerday and Von Solms (2006) examine the classic example of game theory, known as the prisoner's dilemma, in which two prisoners in separate cells face the dilemma of whether or not to be police informants. Without further communication, the two players need to trust each other. If neither party informs, both receive light sentences because of insufficient evidence. If both inform, both receive heavy sentences. If one party defects, they are set free, whilst the other party is convicted based on the informant's evidence. The dilemma of the scenario, according to Flowerday and Von Solms (2006), highlights the issue of trusting the other player without continuous communication.

Similarly, in a supply chain context, where information is freely shared by all members of the supply chain, the benefits to all members is an increased level of trust in the interorganisational relationship and therefore effective and efficient supply chain operations. If no members of the supply chain reveal information, none can benefit from the improved operations described. If some parties share information, whilst others do not, those that have not shared information can benefit far more than those that have shared information. Thus, the ideal situation would be for supply chain partners to share information freely as this would be to the benefit of the entire supply chain.

According to Lewis (1999), this mutual information sharing is likely to occur if all parties will benefit from the relationship in some way, which makes trust an essential prerequisite for information sharing. Poirier (2003) confirms this view by pointing out that trusting that those who access information will act responsibly and for the good of the entire supply chain, is crucial to the success of the collaboration.

Having defined trust and reviewed the importance of trust in supply chains and how information sharing can support this, the study explored these concepts of information sharing and trust within South African based OEMs and their supply chains. 


\section{Evidence of information sharing structures in automotive supply chains}

Most automotive OEMs have made some attempt at information sharing with their entire supply chain. These attempts were used to improve efficiency and effectiveness of supply chain relationships and operations. This section details efforts by six of the automotive OEMs with South African-based facilities, namely:

- BMW

- Ford

- General Motors

- Mercedes-Benz

- Toyota

- Volkswagen.

BMW makes use of a web-based document management system that allows easy, secure access to information worldwide (Awazu, Desouza, Jha, Kim \& Wecht 2007; Kappe 2001). This is of particular importance in the global setting of multinational automotive suppliers. Furthermore, BMW encourages the use of a 'yellow pages' application to locate experts (Awazu et al. 2007; Kappe 2001). This is the most important (and easy to establish) tool for information sharing in multinational automotive supply chains.

Ford's web-based knowledge base is an important tool for dealing with daily problem-solving activities (Jenkins \& Tallman 2010; Coughlan \& Rukstad 2001). The portals and intranet sites ensure that relationships are formed between the necessary people for problem solving to occur (Rethink IT 2004), as well as allowing information access within the supply chain. This is necessary for globally dispersed employees in a multinational automotive supply chain.

General Motors' efforts include the establishment of centres of excellence in key business areas (Jenkins \& Tallman 2010; Coughlan \& Rukstad 2001). Even more important is the documentation of lessons that have been learned and discussions of the best practices that is encouraged amongst all the supply chain stakeholders (Coughlan \& Rukstad 2001).

Mercedes-Benz's efforts have an interesting history. Initiatives embarked upon include knowledge and information resource mapping, and Communities of Practice (CoPs) that focus on particular situations (Coughlan \& Rukstad 2001). Furthermore, the company has identified knowledge areas that require support by the existing CoPs (Jenkins \& Tallman 2010; Coughlan \& Rukstad 2001). Mercedes-Benz's initiatives hold value for the multinational automotive supplier in terms of bringing geographically dispersed employees and suppliers together to solve problems and ensure the free flow of information within their supply chain.

The success of Toyota's information management initiatives highlights the relevance of information sharing in the automotive sector. These information-sharing practices have allowed Toyota to ensure collaboration and realise significant benefits for the entire supply chain (Liker 2004).
Furthermore, their know-how database allows employees to explore previous problem solving attempts (Liker 2004). This central repository is an important source of information for their entire supply chain network.

Volkswagen has also made use of a web-based knowledge base for query handling (Gregoire \& Cohen 2001). Volkswagen's efforts focus on the distribution of the necessary information and solutions to problems throughout the organisation and supply chain (Volkswagen 2007). Similar to BMW, Volkswagen has implemented a 'yellow pages' application, which, together with expert 'rooms' encourages collaboration for problem-solving activities (Volkswagen 2007).

Although this literature points to a free flow of information from the OEM to suppliers, little or no mention is made of information flowing from, or amongst, suppliers. In fact, Toyota appears to be the only automotive manufacturer to have information flowing freely within the supply chain their continued dominance of the market might be attributed to this (Liker 2004). The case study in the next section provides evidence of poor information sharing within the supply chain.

\section{Case study}

In the case study detailed below, no evidence was found of free information flow in the interorganisational relationships in a South African automotive supply chain. The event studied had the potential to shut down operations at the OEM and thus have a ripple effect on the operations of other members of the supply chain. Information gained was not shared with other members in the supply chain, thereby having a negative impact on operations.

Observations relevant to this study centre on one particular instance - the hard drive failure of a production machine that caused production to stop for over a week at the plant under discussion. This resulted in major losses as replacement products had to be shipped in from other manufacturing plants in order to supply the local automotive OEM and prevent incurring further penalties. This issue is typical of problems encountered at this company. If information regarding this failure had been shared with the entire supply chain, all parties could have been able to adjust manufacturing for this period. This was not carried out, as the supplier was concerned that the OEM would source a similar product elsewhere for production and thus jeopardise future contracts between the supplier and OEM.

In order to get the equipment to function correctly, collaboration was required from a number of role players, including, (1) staff at the manufacturers of the machine, (2) the manufacturers and local agents of the industrial computer that runs the machine,(3) subject matter experts at the company's head office in order to install the necessary software (4) and a local IT company to provide technical services. 
The effects of a lack of trust can be seen in this supply chain relationship. Had the supplier had a trust relationship with the OEM and other suppliers in the supply chain, information regarding the machine failure and possible production stoppages could have been shared. This would have allowed the OEM, and subsequently the entire supply chain network, to adjust production schedules, for example, by manufacturing a different vehicle that did not make use of the supplier's components. The lack of trust in this supply chain resulted in production shutting down temporarily at the OEM and the supplier incurring the costs of shipping components from an overseas-based partner and penalties associated with halting production at the OEM. Based on this analysis, the next section proposes a way towards a more competitive supply chain. This is then related to the organisational information processing theory and game theory that has been discussed in a previous section.

\section{The way forward for competitive supply chains}

As Dubey and Jain (2005) and Peterson (2002) point out, the modern supply chain needs to be collectively competitive. In the chain organism supply chain model mentioned previously (Peterson 2002); the existence of trust in the interorganisational relationship is paramount to the competitiveness of the supply chain.

Where adequate levels of trust exist in the interorganisational relationships, information sharing amongst supply chain partners is maximised. With increased information sharing, transactional costs are reduced and efficiency improved, thereby allowing the supply chain to compete effectively.

At the same time, the more information that is shared, the more trust can be established within the supply chain. Having previously established the role IT has in facilitating information sharing (and thereby enhancing trust), this vital component cannot be ignored. This cyclical relationship between trust and information sharing and the underlying support role of IT is represented in Figure 1.

This view is confirmed by the organisational information processing theory discussed in a previous section, whereby uncertainty in the relationship can be reduced by increasing access to information (Premkumar et al. 2005). This allows the supply chain to improve decision-making and thereby improve operations.

In light of the game theory and the prisoner's dilemma discussed in a previous section, the supplier's choice to cooperate and supply information willingly is directly related to the amount of information available and therefore the level of trust that each of the supply chain partners places in the others. If all supply chain members trust each other, information is shared, and maximum gain for the entire supply chain can be realised in terms of efficiency and effectiveness of operations and competitiveness.

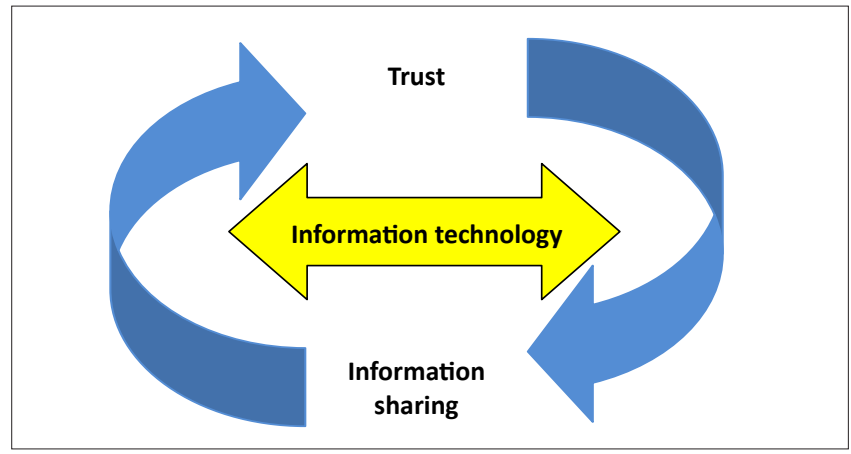

FIGURE 1: The trust-information sharing relationship.

\section{Conclusion}

This paper has shown how several works have highlighted the importance of trust in a supply chain and the effects of diminished trust on supply chain operations. All these studies suggest that increasing the level of trust in the interorganisational relationship is required. The relationship between trust and information sharing is important in the context of our research. Several works have highlighted benefits and concerns regarding sharing information amongst supply chain partners, at the same time noting a relationship between trust and information sharing in a singular direction.

This paper considered the relationship between the two concepts (trust and information sharing) and looked at how they influence each other. The use of IT to support this relationship was also established. In order to have a sufficient level of trust in a relationship, a significant level of information sharing is required. Better decision-making can occur if there is sufficient information, and the resultant improved operational performance experienced, results in improved trust in the supply chain partners that have shared the information. Conversely, the sharing of information will only occur if there is a sufficient level of trust amongst supply chain partners. If there is insufficient trust in supply chain partners, there will be unwillingness to share information. Thus, the relationship between trust and information sharing is cyclical - it is not a relationship that occurs in a singular direction as established by the existing literature.

An example of the effects of a lack of trust in a supply chain relationship and the consequential lack of information flow, were provided in a case study of an Eastern Cape based automotive supplier. This led to a proposed way forward for competitive supply chains, in which building trust in the supply chain is essential for improved information flow. This, in turn, leads to improved supply chain performance and competitiveness. Furthermore, this situation leads to improved trust, allowing the supply chain partnership to be mutually beneficial.

\section{References}

Agarwal, A. \& Shankar, R., 2003, 'On-line trust building in e-enabled supply chains', Supply Chain Management: An International Journal, 8(4), 324-334. doi:10.1108/13598540310490080 
Awazu, Y., Desouza, K., Jha, S., Kim, J. \& Wecht, C., 2007, 'Roles of Information Technology in Distributed and Open Innovation Process' in J. Burke \& M Shaw (eds.), 13th Americas Conference on Information Systems AMCIS 2007 Shaw (eds.), 13th Americas Conference on Information
proceedings, Keystone, USA, August 9-12, 2007, pp. 1-10.

Barnes, J. \& Morris, M., 2008, 'Staying alive in the global automotive industry: what can developing economies learn from South Africa about linking into global automotive value chains?', The European Journal of Development Research 20(1) 31-55. doi:10.1080/09578810701853157

Black, A., 1998, 'The impact of trade liberalization on the South African automotive industry', paper presented to the TIPS Policy Forum, Gauteng, South Africa, 9-11 September.

Africa Research Bulletin, 2010, 'Economic, Financial and Technical Series', Company Brief: General 47(3), pp. 18645-18648, viewed 15 January 2011, from http:// onlinelibrary.wiley.com/doi/10.1111/j.1467-6346.2010.03227.x/abstract

Burnes, B. \& West, P., 2000, 'Applying organisational learning: Lessons from the automotive industry', International Journal of Operations and Production Management, 20(10), 1236-1251. doi:10.1108/01443570010343762

Cheng, T.C.E., Lai, K-H. \& Singh, N., 2007, 'Intra-organizational perspectives on IT-enabled supply chains', Communications of the ACM, 50(1), 59-65. doi:10.1145/1188913.1188918

Chu, S-Y. \& Fang, W-C., 2006, 'Exploring the relationships of trust and commitment in supply chain management', The Journal of American Academy of Business, Cambridge, 9(1), 224-228.

Cooper, D.R. \& Schindler, P.S., 2003, Business Research Methods, 8th edn., McGrawHill/Irwin, New York, NY.

Coughlan, P. \& Rukstad, M.G., 2001, DaimlerChrysler Knowledge Management Strategy, Harvard Business School Publishing, Boston, MA.

Covey, S.M.R., 2008, The speed of trust: The one thing that changes everything, Free Press, New York, NY.

Davis, J.H., Mayer, R.C. \& Schoorman, F.D., 2007, 'An Integrative Model of Organizational Trust: Past, Present and Future', Academy of Management Review, 32(2), 344-354. doi:10.5465/AMR.2007.24348410

Department of Trade and Industry, 2005, Current Developments in the Automotive Industry 2004, viewed 15 January 2011, from http://apps.thedti.gov.za/ publications/automotiveindustry.pdf

Department of Trade and Industry, 2010,, Media release: Minister Davies approves Automotive Investment Scheme Guidelines, viewed 15 January 2011, from http:// apps.thedti.gov.za/mediareleases/AIS media.pdf

Dubey, A. \& Jain, K., 2005, 'Supply chain collaboration: A governance perspective', Supply chain forum: An international journal, 6(2), 50-57.

Fachinelli, A.C., Ueltschy, L.C. \& Ueltschy, M.L., 2007, 'The impact of culture on the generation of trust in global supply chain relationships', The Marketing Management Journal, 17(1), 15-26.

Fedorowicz, J. \& Ghosh, A., 2008, 'The role of trust in supply chain governance', Busines Process Management Journal, 14(4), 453-470. doi:10.1108/14637150810888019

Fingar, C. (2002), 'Car wars' in ifDi magazine, viewed 02 July 2006, from http://www. fdiintelligence.com/Archive/Car-wars

Flowerday, S. \& Von Solms, R., 2006, 'Trust: an Element of Information Security', in S Fischer-Hubner, K. Rannenberg, L. Yngstrom and S. Lindskog (eds.), Security and Fischer-Hubner, K. Rannenberg, L. Yngstrom and S. Lindskog (ed.)
Privacy in Dynamic Environments, pp. 87-98, IFIP, Springer, USA.

Ford Motor Company (2005), 'Challenges facing the automotive industry' in Ford Sustainably Report, viewed 30 March 2006, from http://corporate.ford.com/ doc/2004-05 sustainability report.pdf

Franse, R., 2006, 'The response of an original equipment manufacturer to the moto industry development programme: A case study', MA dissertation, Department of Business Management, Rhodes University.

Gao, J. \& Lee, J.D., 2005, 'Trust, information technology, and cooperation in supply chains', Supply Chain Forum: An international Journal, 6(2), 82-89.

Gregoire, C. \& Cohen, G., 2001, 'Audi Licenses Hyperwave's Collaborative Knowledge Management System', in Let's see if they use it now: eKnowledge Infrastructure Enables AUDI Employees to Answer Customer..., viewed 15 January 2011, from $\mathrm{http}: / /$ forums.audiworld.com/showthread.php?t=1815029

Han, Z., Liu, K.J.R., Sun, Y.L. \& Yu, W., 2006, 'A Trust Evaluation Framework in Distributed Networks: Vulnerability Analysis and Defense Against Attacks', in E. Monteiro \& J.L. Gonzalez (eds.) IEEE INFOCOM Conference on Computer Communication Proceedings, Barcelona, Spain, April 23-29, 2006, pp. 1-13.

Jenkins, M. \& Tallman, S., 2010, 'The Shifting Geography of Competitive Advantage: Clusters, Networks and Firms', Journal of Economic Geography, 10(4) 1-20.
Jharkharia, S. \& Shankar, R., 2004, 'IT enablement of supply chains: modeling the enablers', International Journal of Productivity and Performance Management 53(8), 700-712. doi:10.1108/17410400410569116

Kappe, F., 2001, 'Knowledge management: A practical example at BMW', paper presented at the I-Know 2001, Graz, Austria, 12-13 July 2001.

Kazi, A.S. \& Wolf, P. (eds.), 2004, 'Real-life Knowledge Management: Lessons from the Field', viewed 20 July 2006 from, http://www.knowledgeboard.com/lib/3236.

Kwon, I-W. G. \& Suh, T., 2005, 'Trust, commitment and relationships in supply chain management: A path analysis', Supply chain management: An international Journal, 10(1), 26-33.

Lewis, J.D., 1999, Trusted Partners: How Companies Build Mutual Trust and Win Together, The Free Press, New York, NY.

Liker, J.K., 2004, The Toyota Way: 14 Management Principles from the World's Greatest Manufacturer, McGraw-Hill, New York, NY.

Liu, X-F., 2007, 'Study on the application of information technology in supply chain management', Journal of US-China Public Administration, 4(1), 72-76.

Lorentzen, J., 2006, Multinationals on the Periphery: DaimlerChrysler South Africa, Human Capital Upgrading and Regional Economic Development, Human Sciences Research Council Press, Cape Town.

Mak'Ochieng, A.A., 2003, 'A case study of the strategic nature of DaimlerChrysle South Africa's corporate social investment programmes in the local communities of the Border-Kei region in the Easter Cape province', MA dissertation, Dept. of Business Management, Rhodes University.

Mangold, P., 2009, 'South African Automotive Week: Mercedes-Benz', in South African Automotive Week, viewed 27 April 2009, from http://www.saaw.co.za/News/0904-27/mercedes-benz.aspx.

McEvily, B. \& Tortoriello, M., 2011, 'Measuring trust in organisational research: Review and recommendations', Journal of Trust Research, 1(1), 23-63. doi:10.1 080/21515581.2011.552424

Naesens, K., Pintelon, L. \& Taillieu, T., 2007, 'A framework for implementing and sustaining trust in horizontal partnerships', Supply chain forum: An international journal 8(1), 32-44.

Pagano, A. \& Zagnoli, P., 2001, 'Modularization, Knowledge Management and Supply Chain Relations: The Trajectory of a European Commercial Vehicle Assembler' viewed 10 April 2006, from http://citeseerx.ist.psu.edu/viewdoc/download?doi viewed 10 April 2006, from $\mathrm{http}: / /$ cites
$=10.1 .118 .4772 \& \mathrm{rep}=$ rep1\&type=pdf

Peterson, H.C., 2002, 'The "learning" supply chain: Pipeline or pipedream', American Journal of Agricultural Economics, 85, (5), 1329-1336. doi:10.1111/1467Journal of
8276.00398

Poirier, C.C., 2003, The Supply Chain Manager's Problem-Solver, CRC Press, Florida, FL.

Premkumar, G., Ramamurthy, K. \& Saunders, C.S., 2005, 'Information processing view of organizations: An exploratory examination of fit in the context', Journal of Management Information Systems, 22(1), 257-294.

Rethink IT, 2004, 'The car industry drives forward with knowledge management Masterclass' in Rethink IT, viewed 18 July 2006, from http://findarticles.com/p/ articles/mi_mOPAT/is_2004_March/ai_114699548/

Ryu, S., 2006, 'The effect of external and internal environments on interfirm governance', Journal of business-to-business marketing, 13(2), 67-89. doi:10.1300/J033v13n02 04

Sahay, B.S., 2003, 'Understanding trust in supply chain relationships', Industrial management and data systems, 103(8), 553-563. doi:10.1108/02635570310497602

Smeltzer, L.R., 1997, 'The Meaning and Origin of Trust in Buyer-Supplier Relationships', International Journal of Purchaising and Materials Management, Winter, $\mathrm{pp}$. internation.

Volkswagen, 2007, 'Knowledge Management: Knowledge at Volkswagen', viewed 01 September 2007 from http://www.vw-personal.de/www/en/wissen/ wissensmanagement.htm

Wang, E.T.G. \& Wei, H-L., 2007, 'Interorganizational governance value creation Coordinating for information visibility and flexibility in supply chains', Decision Sciences, 38(4), 647-674. doi:10.1111/j.1540-5915.2007.00173.x

Ward, A., 2009, 'South African Automotive Week: Toyota', viewed 28 April 2009, from http://www.saaw.co.za/News/09-04-28/toyota.aspx.

Yin, R.K., 2003, Case Study Research: Design and Methods, 3rd edn, Volume 5, SAGE Publications, California, CA. 